\title{
Situações de trabalho e relatos de dor entre feirantes de confecções
} Work situation and pain reports among clothing merchants
Situaciones de trabajo e relatos de dolor entre los vendedores de prendas
de vestir

\author{
Renata Guimarães de CARVALHO ${ }^{1, a}$ \\ Iara Andrade de OLIVEIRA ${ }^{\text {b }}$ \\ Luciana Maria MAIA ${ }^{\mathrm{b}}$ \\ Regina Heloisa MACIEL ${ }^{\mathrm{b}}$ \\ Tereza Rocha MATOS ${ }^{\mathrm{b}}$
}

Universidade Federal do Ceará, Sobral, CE, Brasil ${ }^{a}$, Universidade de Fortaleza, Fortaleza, CE, Brasil ${ }^{b}$

ReSumO Este estudo objetiva descrever a situação de trabalho de feirantes que atuam na informalidade em uma feira de roupas no centro da cidade de Fortaleza, bem como levantar indícios de impactos dessa realidade na saúde desses trabalhadores, especificamente relatos de dor. Foi desenvolvida uma pesquisa do tipo exploratória e qualitativa, com o uso das técnicas de observação direta e entrevista com roteiro estruturado, realizadas no ambiente de trabalho dos feirantes. Para tratamento dos dados, utilizou-se a análise de conteúdo com as seguintes categorias: situações de trabalho (condições e organização do trabalho), relatos de dor e o trabalho como feirante. Entre os resultados obtidos, destaca-se que: (a) o grupo de trabalhadores entrevistados é muito diversificado no que se refere à idade, escolaridade e renda; (b) os feirantes apresentam categorias de trabalho distintas; (c) o espaço de trabalho influencia a forma como a atividade é organizada cotidianamente; e (d) os relatos dos feirantes indicam a presença de dor osteomuscular, mas a necessidade de não interromper o trabalho prevalece em relação aos cuidados com a saúde. Conclui-se que a construção de determinadas formas de ordenamento do trabalho no ambiente da feira indica uma capacidade de autonomia e organização efetivada pelos trabalhadores, mas que não suprimem a condição de precariedade e de informalidade em que estão inseridos.

Palavras-chave:

Situação de trabalho; saúde; informalidade; feirante.

Abstract This study aims to describe work situations among market stallholders operating informally in a clothing fair in the city center of Fortaleza, and to identify signs of health related issues linked to this reality. A qualitative exploratory research study was conducted, using direct observation and structured interview techniques, performed in the working environment of the stallholders. The data were analyzed by means of a content analysis of interviews and observations. The categories used were: work situations, containing work and organizational conditions, and reports on pain and merchant work. The results pointed out that: (a) the group of workers interviewed is very diverse in terms of age, education, and income; (b) the stallholders present distinct informality categories; (c) the place where they work influences the way the work is organized on a daily basis; and (d) the discourses indicate the presence of musculoskeletal pain, but the necessity of not interrupting the work prevails over health concerns. It is concluded that the construction of specific forms of work organization in the fair environment indicates worker capacity for autonomy and effective organization, but does not reduce the precarious and informal conditions in which they are placed.

Keywords:

Work situation; health; informality; market stallholders. 
Este estudio pretende describir la situación de trabajo de los vendedores que actúan en la informalidad en un mercado de ropa en el centro de la ciudad de Fortaleza, así como hacer un levantamiento de indicios de impactos de esta realidad en su salud, específicamente lo que dice respecto a los relatos de dolor. Se desarrolló un estudio de tipo exploratorio y cualitativo, con el uso de las técnicas de observación directa y entrevista estructurada, realizadas en el entorno de trabajo de esos profesionales. Para el tratamiento de los datos, se utilizó el análisis de contenido con las siguientes categorías: situaciones de trabajo (condiciones y organización del trabajo), relatos de dolor y el trabajo realizado. Entre los resultados observados se destaca que: (a) el grupo de los trabajadores entrevistados es muy variado en cuanto a su edad, nivel de escolaridad e ingresos; (b) los vendedores cuentan con categorías distintas de informalidad; (c) el local de trabajo influencia la forma como la actividad es organizada cotidianamente; (d) los relatos de los vendedores indican la presencia de dolor músculo-esquelético, pero prevalece la necesidad de no interrumpir el trabajo en relación con la atención a la salud. Se concluye que la construcción de determinadas formas de organización del trabajo en el entorno del mercado indica una capacidad de autonomía y organización efectuada por los trabajadores, pero no elimina la condición de precariedad y de informalidad en las que están inseridos.

Palabras-clave:

Situaciones de trabajo; salud; informalidad; vendedor.

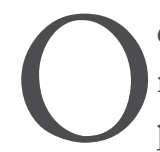

cenário atual do mundo do trabalho integra-se a transformações econômicas, políticas e sociais no sistema capitalista. Associado ao processo de reestruturação produtiva, no qual a realidade da produção mundial se modificou, ocorreram o enfraquecimento da seguridade social e a ampliação das relações laborais precarizadas. Seguindo as tendências mundiais, o sistema produtivo brasileiro não só se equipou com mais tecnologia, mas também modificou as formas de gestão do trabalho, o que favoreceu a redução de empregos formais (Antunes, 2008; Navarro \& Prazeres, 2010).

Inserida nesse panorama, a noção de informalidade envolve aspectos heterogêneos e expressões como setor informal, processo de informalidade, atividades não fordistas, economia subterrânea, economia informal e nova informalidade (Alves \& Tavares, 2006; Araújo \& Lombardi, 2013; Cacciamali, 2000; Filgueiras, Druck, \& Amaral, 2004; Krein \& Proni, 2010). Os sujeitos que desenvolvem essas atividades têm sido denominados de várias formas, como: trabalhadores autônomos, assalariados sem registro, temporários, microempregadores, trabalhadores do terceiro setor, trabalhadores que desenvolvem atividades baseadas em economia solidária ou em pequenas unidades produtivas que usam a força de trabalho de membros da família. São trabalhadores que, na maioria das vezes, atuam em ambientes de insegurança laboral; não contam com as proteções vinculadas ao contrato formal de trabalho; têm condições de trabalho inadequadas; cumprem extensas jornadas de trabalho; e os rendimentos do trabalho são baixos. Todos esses aspectos podem causar prejuízos à saúde e à segurança desses trabalhadores (Krein \& Proni, 2010).

Estudos apontam que, mesmo estando doentes, trabalhadores informais procuram não se ausentar das atividades de trabalho (Díaz, Guevara, \& Lizana, 2008; Rosa \& Mattos, 2010). Para Díaz et al. (2008), esse fato se relaciona à falta de segurança social e de garantias que assegurem a eles serem remunerados quando afastados por motivos de saúde. A crença de que as condições precárias de trabalho são inevitáveis e a negação da existência de problemas de saúde por medo da perda da garantia de sobrevivência também são elementos presentes nesse fenômeno (Assunção, 2003; Minayo-Gomez \& Thedim-Costa, 1997).

A informalidade é uma realidade bastante expressiva no Brasil. Na primeira década de 2000, mesmo com a criação de 21 milhões de postos de trabalho formais e a diminuição das taxas de desemprego, o nível de informalidade era significativo (Pochmann, 2012). Segundo dados do Instituto Brasileiro de Geografia e Estatística (IBGE, 2013), na média nacional, 23\% das pessoas trabalhavam por conta própria e 3,1\% se descreviam como trabalhadores familiares que não recebiam remuneração. Na região Nordeste esse percentual estava acima da média nacional, indicando 29,3\% de trabalhadores por conta própria e 4,9\% de trabalhadores familiares.

Longe do formato do emprego típico, com contrato, prescrição de tarefas, local e hierarquias definidos e amparo da legislação (Galeazzi, 2006), os trabalhadores informais experimentam condições (instalações físicas, iluminação, temperatura, exposição a ruídos ou gases) e formas de organização laboral (divisão de tarefas, relações de hierarquia, comunicação, ritmo de trabalho) que compõem uma situação de trabalho (Abrahão, Sznelwar, Silvino, Sarmet, \& Pinho, 2009) bastante heterogênea e diversificada, como é característico da informalidade. 
É nesse contexto que emergem práticas e estratégias que buscam desenvolver normas de convivência entre os trabalhadores informais, que possibilitem um mínimo de ordenação de seu trabalho. Trata-se de microcadeias produtivas da nanoeconomia que podem ser interpretadas como uma "batalha cotidiana para criar possibilidades, o dia a dia dos microeventos da economia popular, a solidariedade que vem do reconhecimento da situação do outro" (Spink, 2009, p. 231). São formas de organização estabelecidas coletivamente pelos trabalhadores no cotidiano do trabalho e que buscam soluções que garantam sua dignidade e subsistência material. São "empreendimentos caseiros” construídos à margem da regularização formal, equilibrados por meio de negociações cotidianas com clientes, fornecedores, parceiros de trabalho e concorrentes, poder público, entre outros, mas que atendem bem, com eficiência, à demanda da comunidade em que se instalam (Spink, 2009).

Esse tipo de organização de trabalho tem sido descrita na literatura brasileira ora como "empresa-rua", criada pelos camelôs nos espaços públicos da cidade de São Paulo (Salvitti, Viégas, Mortada, \& Tavares, 1999, p. 22), por exemplo, ora como "bagunça organizada" da feira livre (Sato, 2007, p. 98) ou, ainda, como redes sociais de apoio a vendedores ambulantes que fornecem também um modo de organização da atividade informal (Barroso, 2011; Lima \& Conserva, 2006). Em comum, essas situações de trabalho informal se sustentam em um modelo de organização alternativo ao modelo de gestão formal e são inspirados em "modos operatórios que se estruturam nas trajetórias de vida e de trabalho" (Conserva, 2004, p. 270).

Partindo da importância de compreender essa realidade, tomou-se como objeto de investigação o ambiente de uma feira de confecções de grande porte, sediada na cidade de Fortaleza (CE), conhecida como Feira da Sé. No campo da informalidade, os feirantes formam uma nova classe de trabalhadores, com características próprias, relativas ao seu cotidiano de vida e de trabalho (Souza, 2010). O estudo das feiras não é recente e atrai a atenção de pesquisadores de diferentes disciplinas que, partindo de interesses diversos, procuram ampliar a compreensão acerca dos costumes e das formas de organização social de diferentes grupos e comunidades (Costa, 2013; Ferreira, Marques, \& Guerra, 2015; Guimarães \& Mesquita, 2009; Lomba \& Nobre-Júnior, 2013; Ramos, 2008; Rezende, 2001; Santos, 2005; Sato, 2007; Silva, 2003).

No Nordeste brasileiro destacam-se as feiras de confecções de roupa. Lira (2008) explica que nesse comércio predominam pequenas empresas de confecção que abastecem as bancas das feiras com produtos a preços baixos, mas que movimentam um mercado de grandes proporções. Em sua origem, esse comércio ficou conhecido como a feira que possui produtos simples, de qualidade inferior e preços acessíveis a camadas da população de baixa renda. Atualmente, esses produtores dividem o espaço com outros vendedores que comercializam roupas de melhor qualidade e preços mais elevados.

A Feira da Sé teve início com uma pequena quantidade de artesãos que vendiam seus produtos em frente à Catedral Metropolitana de Fortaleza, localizada em uma região histórica e turística, no centro da cidade. Esse grupo logo se ampliou, tomando ruas e avenidas e tornando necessária a constante intervenção do poder público em função da ocupação desordenada do espaço (Santos, Silva, \& Silva, 2011). As atividades dessa feira ocorrem no período noturno e adentram a madrugada, entre quartas e quintas-feiras, e sábados e domingos. A feira faz parte de uma complexa rede de comércio popular e informal e atrai compradores de vários estados das regiões Norte e Nordeste, além de países da África e Guiana Francesa (Chaves, 2012), podendo contar, em sua totalidade, com até 7 mil feirantes nos períodos de alta estação.

Partindo dessas considerações preliminares acerca do trabalho informal e da Feira da Sé, este artigo tem como objetivos descrever a situação de trabalho de feirantes que atuam na informalidade no espaço dessa feira e levantar indícios de impactos dessa realidade em sua saúde, especificamente relatos de dor.

\section{MÉTODO}

Este estudo é resultado de uma pesquisa qualitativa e exploratória, realizada no espaço da Feira da Sé, localizada no centro de Fortaleza. Considerando que se buscou compreender a realidade de trabalho construída pelos feirantes, optou-se pela investigação qualitativa. Destaca-se, entretanto, que foram utilizados alguns indicadores quantitativos em relação aos relatos de dor e algumas características sociodemográficas, mas que tiveram por objetivo apenas a descrição da realidade de trabalho do grupo estudado e não a sua generalização.

\section{Participantes}

Os participantes da pesquisa são feirantes que atuam em bancas nas ruas e em galpões nas imediações da feira. Foram convidados tendo como critérios a conveniência das pesquisadoras e a facilidade de acesso, 
considerando seu interesse e disponibilidade para participar da pesquisa. Como critério de seleção, de modo a garantir o caráter informal das atividades desenvolvidas pelos participantes, estabeleceu-se que não fariam parte da pesquisa feirantes com carteira de trabalho assinada e/ou que recolhiam as taxas referentes ao seguro social (INSS).

Dessa forma, participaram da pesquisa 35 feirantes que trabalhavam de modo informal. Entre eles, 24 $(68,6 \%)$ eram mulheres e $11(31,4 \%)$ eram homens. Essa divisão percentual não foi intencional, já que a amostra foi definida por conveniência, mas reflete a expressiva participação feminina na feira. A idade das mulheres variou entre 18 e 57 anos, sendo a média 35 anos ( $D P=12,11$ anos). Já entre os homens, as idades variaram de 18 a 51 anos e a média foi de 34 anos ( $D P=11,64$ anos). No que se refere à escolaridade, a maioria dos participantes, 19 (54,3\%), tinha ensino médio completo, 5 (14,3\%) iniciaram esse nível escolar, mas não o concluíram. Em relação ao ensino fundamental, 1 havia concluído e $8(22,8 \%)$ não o concluíram. Apenas um entrevistado tinha ensino superior completo em administração e outro havia iniciado essa graduação, porém não a concluiu.

Não foi possível calcular a média de renda dos participantes, pois muitos não sabiam exatamente quanto recebiam. Mesmo entre aqueles que responderam sobre a renda, muitos não sabiam diferenciar a renda das vendas na banca de seus rendimentos pessoais. Além disso, alguns trabalhadores calculavam a renda por mês, outros por semana e outros por diárias recebidas, revelando que a lógica inerente ao trabalho informal é bem diferente do modelo de emprego e salário fixo mensal. O problema da investigação de rendimentos, principalmente em relação à subestimação do valor recebido, já é conhecido: "quanto mais elevado o rendimento, maior o grau de subestimação do seu valor” (Rocha, 2003, p. 208). Além disso, o grau de subestimação depende da natureza do rendimento, sendo maior quando se trata de rendimentos do trabalho informal e de capital. Assim, as respostas dos participantes sobre sua renda variaram de 20 reais por diária até 20 mil reais por mês. No caso desta pesquisa, acredita-se que essa variação não está ligada necessariamente à subestimação dos valores recebidos, mas, sobretudo, à variedade de categorias dos feirantes entrevistados. Em relação aos rendimentos dos donos das bancas e confecções, a maioria não sente necessidade de diferenciar lucros e despesas ou, até mesmo, despesas pessoais e despesas do negócio. Isso não quer dizer que os donos não percebam se estão lucrando ou tendo prejuízos, apenas que não diferenciam muito bem as despesas que incorrem no negócio.

No que diz respeito ao tempo de trabalho no ramo de vendas de confecções, as respostas variaram de duas semanas até 30 anos de experiência. A média de tempo de trabalho era de 6,3 anos ( $D P=7,25$ anos). A amplitude de variação do tempo de trabalho na feira provavelmente está relacionada às diferentes categorias de trabalhadores, como no caso da renda obtida com o trabalho, além de sugerir que a atividade tem sido ou uma forma duradoura de ocupação, no caso dos donos de confecções ou de barracas, ou uma estratégia de sobrevivência em momentos de crise, no caso dos trabalhadores associados.

\section{Instrumentos e procedimentos}

Os métodos de coleta de dados foram observação direta do ambiente da feira e entrevistas baseadas em roteiro estruturado (Creswell, 2007). O foco da observação recaiu sobre as condições de trabalho nos espaços da feira: climatização, iluminação, limpeza, ruídos, estrutura das bancas, existência de instalações sanitárias e de alimentação. O roteiro de entrevista foi composto por itens sobre dados sociodemográficos e por questões que abordavam a realidade de trabalho do feirante, como local do ponto de venda, quantidade de trabalhadores por banca, tarefas realizadas, instrumentos utilizados e sugestões de melhoria das condições da feira. Especificamente em relação a indícios de impactos na saúde dos feirantes, buscou-se identificar queixas de dores osteomusculares ou desconforto físico. Para este último item, foi apresentado um desenho do corpo humano e solicitado que o entrevistado apontasse o local onde sentia dor ou desconforto. Também foi pedido que indicasse a intensidade e a frequência do sintoma, a partir do seguinte padrão: "dor leve e de vez em quando"; "dor leve, mas contínua"; "dor forte, de vez em quando"; "dor forte e contínua". Os participantes foram abordados em seu próprio local de trabalho e eram, na ocasião, os responsáveis pela comercialização direta de produtos na banca. Sempre que clientes se aproximavam, a entrevista era interrompida, o que se tornou mais uma oportunidade de observação de seu processo de trabalho. As entrevistas foram realizadas individualmente, com auxílio de um gravador digital.

Para tratamento dos dados coletados, após transcrição das entrevistas e da leitura das informações anotadas pelo pesquisador no contato com os feirantes entrevistados, optou-se por utilizar a técnica de análise de conteúdo temática. Especificamente, usou-se a análise categorial temática no processo de codificação das 
unidades de registro e organização de temas emergentes. Considerando o objetivo proposto, dois temas principais surgiram: (a) situação de trabalho, composto por categorias de trabalho na feira e condições e organização do trabalho; e (b) relatos de dor e o trabalho como feirante. A partir desses temas foram delineadas categorias de análise que serviram de base para inferências sobre o objeto de estudo.

Considerando os aspectos éticos referentes a pesquisas envolvendo seres humanos, este estudo foi submetido ao Comitê de Ética. Antes de serem iniciadas as entrevistas com os trabalhadores, eles foram esclarecidos sobre a temática da pesquisa e a procedência dos pesquisadores. Os entrevistados concordaram em participar da pesquisa, assinando um Termo de Consentimento Livre e Esclarecido.

\section{RESULTADOS E DISCUSSÃO}

\section{A situação de trabalho dos feirantes}

\section{Categorias de feirantes}

No momento da entrevista, todos os participantes estavam realizando atividades ligadas diretamente à comercialização de mercadorias. Mesmo assim, identificou-se, a partir das tarefas descritas, a existência de categorias de trabalho diferenciadas que serão usadas para análise. Para fins deste estudo, essas categorias foram designadas como "fabricante", "comerciante" e "vendedor", como exposto na Tabela 1.

TABELA 1. Categorias de trabalho entre feirantes

\begin{tabular}{|c|c|c|}
\hline $\begin{array}{l}\text { Categorias de } \\
\text { trabalho }\end{array}$ & Tarefas realizadas & Detalhamento \\
\hline abricante & $\begin{array}{l}\text { Planejamento e fabricação das mercadorias que serão ven- } \\
\text { didas na feira. } \\
\text { Organização e transporte das mercadorias para a feira. } \\
\text { Limpeza da banca. } \\
\text { Organização e exposição das mercadorias na banca. } \\
\text { Atendimento de clientes. }\end{array}$ & $\begin{array}{l}\text { Trabalham na fabricação das mercadorias e vão } \\
\text { à feira para comercialização. Participam do pla- } \\
\text { nejamento e da confecção das peças. Atuam na } \\
\text { compra de matéria-prima com fornecedores e ne- } \\
\text { gociam parcerias com facções. São responsáveis } \\
\text { pela organização da banca e pela venda na feira. }\end{array}$ \\
\hline
\end{tabular}

Venda das mercadorias.

Fechamento da banca.

Organização e transporte das mercadorias para a feira. Obtenção do espaço da banca (no caso de feirantes da rua). Limpeza da banca.

Organização e exposição das mercadorias na banca. Atendimento de clientes.

Comerciante Venda das mercadorias. Fechamento da banca.
Adquirem com fornecedores as mercadorias que serão comercializadas na feira. São responsáveis pelo ponto da banca e pela venda na feira, seja no galpão ou na rua.
Limpeza, organização e exposição das mercadorias. Atendimento de clientes.

Venda das mercadorias.

Vendedor
Fechamento da banca.
É contratado pelo "dono" da banca para trabalhar Atua prioritariamente no espaço da feira, organizando as mercadorias e realizando a venda. Trabalha por um salário fixo mensal ou como diarista por feira.

O feirante/fabricante é o trabalhador que participa dos meios de produção das mercadorias que vende. A produção pode acontecer de diversas formas: realizada pelo próprio feirante, com a ajuda de familiares no ambiente domiciliar, e em parceria com facções. As facções, em geral, são grupos de costureiras que atuam na informalidade e executam tarefas específicas do processo produtivo, como montagem das peças, colocação de apliques, entre outros. O planejamento do modelo das roupas e a quantidade são determinados pelo feirante/ fabricante. Durante os dias da semana em que a feira não acontece, esse trabalhador se dedica à produção de peças e, em alguns casos, vai a outras feiras do estado comercializar suas mercadorias. 
Uma das entrevistadas revelou um pouco dessa realidade. Estudante de nível superior, trabalha na feira em parceria com a mãe e o padrasto. Atua como vendedora na banca em um galpão na feira da Sé, mas, também, frequenta feiras no interior do estado. Trabalha ainda na produção de peças na pequena confecção que funciona em sua residência. Apesar de atuar ativamente no negócio da família, é a mãe que toma as principais decisões na negociação com clientes, definição de tecidos e modelos que são produzidos.

Outro entrevistado relatou trabalhar há nove anos na feira junto com a esposa, sua principal parceira. Eles são responsáveis pela confecção das roupas comercializadas (utilizando também o serviço de facções), pelo transporte de mercadorias para a feira em carro próprio, pela organização da banca e pela venda direta. Passam todos os dias da semana ocupados com a atividade de confecção dos produtos.

A segunda categoria identificada é a de feirante/comerciante, na qual o trabalhador também é o responsável pela organização da sua banca, mas não participa do processo de produção de mercadorias. Ele adquire os produtos com diversos fornecedores e sua atividade prioritária está relacionada à sua comercialização na feira. No caso da rua, podem contratar alguém para montar e desmontar a barraca e até mesmo para marcar o ponto na rua.

O relato de um dos entrevistados mostra o funcionamento dessa categoria de trabalho. Ele atua há dez anos como feirante e trabalha sozinho na organização de sua banca em um galpão. Transporta seus produtos em carro próprio e os compra diretamente da fábrica, participando de outras feiras em cidades do interior do estado. Outra entrevistada atua na feira há oito anos e utiliza o espaço da rua. Além de comprar as roupas para revenda, também precisa transportar a mercadoria e montar e desmontar sua banca a cada feira. Para isso, conta com a ajuda da filha de 19 anos que a auxilia em todas as atividades.

$\mathrm{Na}$ terceira categoria, a de feirante/vendedor, o trabalhador é contratado pelo dono de um ponto de venda. O trabalhador atua no espaço e período de funcionamento da feira, organizando a banca, atendendo aos clientes, expondo as mercadorias e efetivando a venda. No processo de venda é responsável por mostrar os produtos, contar e conferir as peças vendidas, receber o dinheiro e arrumar a banca novamente. Por exemplo, uma das entrevistadas relatou trabalhar sozinha em uma banca do shopping e receber um salário mínimo. É a responsável pela limpeza do espaço, organização e venda das mercadorias. Seu campo de atuação limita-se à venda e sua principal preocupação é atender bem os clientes.

Outra entrevistada disse trabalhar junto com o marido em uma banca de rua como diarista e ganhar cerca de um salário mínimo por mês. O dono da banca transporta a mercadoria que deve ser vendida. Relatou sofrer com o calor por conta do teto de lona, mas o que mais a incomoda é a lama que se forma no entorno da banca quando chove. Para continuar o atendimento nessa situação, a feirante coloca tábuas de madeira no chão para facilitar a locomoção e senta em cima da banca. Mesmo assim, afirmou gostar do seu trabalho.

$\mathrm{Na}$ categoria feirante/fabricante identificou-se um modo de organização laboral mais sofisticado, que envolve o processo produtivo e a utilização de trabalho direto de componentes da família, seja para a venda na feira ou para a confecção domiciliar das mercadorias. Essa categoria assemelha-se à definição dos "trabalhadores por conta própria" (Alves \& Tavares, 2006, p. 433), produtores de mercadorias que usam mão de obra familiar e podem empregar outras pessoas em pequenas unidades de produção, mesclando formalidade com informalidade.

As categorias feirante/comerciante e feirante/vendedor remetem a características dos "trabalhadores informais tradicionais" (Alves \& Tavares, 2006, p. 431), que dependem de sua força de trabalho e buscam renda para subsistência. Os primeiros se aproximam dos trabalhadores informais "menos instáveis", aqueles que têm um conhecimento prático de sua ocupação e atuam na prestação de serviços, como costureiras, pedreiros, jardineiros e vendedores ambulantes. O feirante/vendedor se aproxima dos trabalhadores informais "instáveis", pois "são recrutados temporariamente, sendo remunerados por peça ou serviço realizado" (Alves \& Tavares, 2006, p. 431).

Pelas características de cada categoria é possível supor que há maior autonomia por parte do feirante/ fabricante, pois ele participa dos meios de produção e é responsável pela organização do trabalho em sua banca. No entanto, a necessidade de produzir e vender suas mercadorias a cada semana para recuperar o dinheiro aplicado, pagar as contas e investir no novo ciclo produtivo o insere em extensas jornadas de trabalho dentro e fora da feira. No caso do feirante/comerciante, que se considera seu "próprio patrão", também há submissão a um ritmo intenso de trabalho para comercializar a cada semana os produtos adquiridos com fornecedores, negociar a compra dos produtos e, até mesmo, participar de várias outras feiras. 


\section{Condições e organização do trabalho}

Por meio da observação direta da rua onde se localiza a feira e os diversos espaços ocupados, constatou-se que o trabalhador, na rua, é responsável pelo transporte de mercadoria e pela montagem e desmontagem da banca. O local ocupado depende de acordos informais efetivados pelos feirantes. Para ajudar nesse processo, há marcações de tinta que definem o espaço que as bancas podem ocupar durante os períodos de funcionamento da feira. As bancas são montadas de forma rudimentar, com o uso de armações de metal e lonas. Em relação ao local de trabalho, a exposição à chuva, à lama, à incidência direta de sol, ao calor e à poluição, bem como a ausência de locais de alimentação e de instalações sanitárias, predispõe os feirantes a riscos ambientais. Além disso, esses trabalhadores sofrem com a insegurança física decorrente do perigo de assaltos. A ausência de locais apropriados para descanso faz muitos feirantes utilizarem o espaço embaixo das bancas para repousarem na madrugada, nos momentos em que o pico de trabalho diminui.

A feira ocupa também o espaço de amplos galpões cobertos que oferecem melhor estrutura aos feirantes. As bancas que compõem esses galpões são compradas e, semanalmente, os proprietários pagam uma taxa de manutenção ao dono do galpão. Além da proteção em relação à chuva e ao sol, os feirantes que dispõem de bancas fixas não precisam montá-las e desmontá-las e podem guardar as mercadorias em armários. Os galpões contam ainda com ventilação, instalações sanitárias e locais para alimentação. $\mathrm{Na}$ área da feira existem ainda os chamados shoppings, onde se situam pequenas lojas, em sua maioria climatizadas, que buscam reproduzir um ambiente de comércio formal, oferecendo mais conforto e segurança para clientes e feirantes. Vale ressaltar que apenas um trabalhador de shopping foi incluído na amostra, pois todos os outros tinham carteira assinada.

De forma geral, nesses três espaços diferenciados da feira, as bancas possuem uma estrutura de pessoal mínima, dispondo de um ou dois trabalhadores durante o seu período de funcionamento. Os instrumentos de trabalho utilizados são basicamente os mesmos, estando diretamente relacionados à organização da banca, à exposição de mercadorias e à efetivação da venda: sacos plásticos, calculadora, vara para manusear manequins suspensos, caderno de anotações, panos e produtos para limpeza e pequenos bancos.

Os feirantes que dispõem de mais recursos se organizam no espaço do galpão, considerado mais seguro. A maioria dos feirantes/fabricantes entrevistados tinha suas bancas nos galpões, indicando uma posição de melhor estrutura econômica. Os feirantes/vendedores, especialmente os diaristas que trabalham no espaço da rua, encontram-se em situação mais vulnerável por estarem sujeitos ao dono da banca, pela instabilidade de seus baixos rendimentos e pelas condições de trabalho mais precárias a que ficam submetidos.

O item da entrevista sobre sugestões de melhoria revelou um aspecto bem peculiar da relação entre os feirantes do galpão e da rua. Além da prevalência dos relatos sobre a necessidade de melhorias das condições de trabalho, como, por exemplo, o aumento na estrutura dos galpões, identificou-se também um discurso que sugere uma situação de conflito entre esses feirantes. Para os feirantes dos galpões, é necessária a retirada dos feirantes da rua, pois eles são percebidos como uma concorrência desleal, já que não pagam nenhum tipo de taxa e têm acesso mais direto aos clientes. Além disso, criam um obstáculo físico para o transporte de mercadorias e para o ingresso de pessoas nos galpões. Entre os feirantes da rua, as sugestões de melhoria também apontam para a mesma necessidade, ou seja, sair da rua. No entanto, o intuito, nesse último caso, é conseguir a transferência para um local mais organizado e menos inseguro, na própria feira.

Esses aspectos apontam para a delicada relação de competição entre trabalhadores que ocupam o mesmo ambiente e buscam os mesmos clientes. Tal como indicado nos estudos de Garcia et al. (2010), sobre vendedoras ambulantes, e de Sato (2007), sobre processos de organização na feira livre, as relações de amizade e de apoio mútuo nas pequenas necessidades são permeadas pela competição e pela busca de espaço para trabalhar.

\section{Relatos de dor e o trabalho como feirante}

Quando questionados sobre se sentiam alguma dor e/ou desconforto no corpo, os entrevistados que responderam de forma positiva ( 27 feirantes, $77,14 \%$ dos participantes) relataram sentir mais dores nos membros inferiores, na coluna e na cabeça. Em relação às possíveis causas da dor, as respostas possibilitaram a identificação de três categorias que expressam diferentes impressões sobre a relação que os feirantes fazem, ou não, entre o seu trabalho e as dores indicadas: (a) causas relacionadas diretamente com a atividade; (b) causas que, embora associadas ao trabalho, não são apontadas dessa forma pelos entrevistados; e (c) causas relacionadas a problemas de saúde e a aspectos específicos não relacionados ao trabalho. 
$\mathrm{Na}$ maioria dos relatos da primeira categoria as dores são atribuídas ao levantamento de peso ou à posição para exercer as atividades de trabalho. Como exemplo dessa categoria, uma das entrevistadas relatou ter dor leve, de vez em quando, nas costas e no joelho, tendo atribuído essas dores à posição sentada e à forma como dorme sobre as mercadorias ou na banca dentro do galpão. Outra trabalhadora relatou dores em diversos locais do corpo, associadas tanto às tarefas realizadas quanto às condições de trabalho. Ela citou dor na coluna e no calcanhar, por conta do peso das mercadorias, relacionou sua dor de cabeça ao clima quente e as dores nos pés ao fato de precisar ficar em pé para atender os clientes, já que quando fica sentada poucas pessoas se aproximam. Na fala de outra participante, a causa de sua dor de estômago e gastrite foi atribuída à má alimentação disponível aos trabalhadores no ambiente da feira.

Como identificação de relatos referentes à segunda categoria, tem-se como exemplos as falas de uma entrevistada que afirmou ter dor no fim da coluna devido à posição de sentar, levantar e agachar. Outra trabalhadora indicou ficar com dormências nos pés ao passar muito tempo sentada e, ainda, outra relatou sentir dores leves e contínuas na coluna, também por ficar muito tempo sentada. Embora as causas apontadas sejam elementos presentes no cotidiano de trabalho dos feirantes, não houve, por parte dos entrevistados, reconhecimento direto de que o trabalho na feira possa estar relacionado à origem da dor.

Integrando a terceira categoria, algumas feirantes associaram a causa da dor a problemas de saúde existentes há anos ou com situações bastante específicas. Uma delas indicou o seu problema de escoliose como causa de suas dores na coluna; outra entrevistada também fez essa associação, destacando que tem o problema desde os 12 anos de idade. Para um dos participantes, a causa da dor leve e contínua que sente no corpo todo é o seu "bico de papagaio". Nesses casos, o diagnóstico do problema de saúde é usado como justificativa para uma dor que parece ser natural e irremediável para o trabalhador. Para outro entrevistado, a causa de sua dor de cabeça é a falta do uso de óculos de grau. Já outro relatou a preocupação com a família como sendo a causa de suas dores de cabeça. Ainda, houve relatos que associavam dores na coluna ao colchão da cama e dores de joelho ao futebol ou ao salto do sapato. Nesses casos, há o reconhecimento da dor, mas a percepção de sua origem está totalmente excluída da realidade de trabalho.

Por meio dos relatos de dor, percebe-se que sentir dores é um fato corriqueiro entre os feirantes, embora a percepção das causas tenha apresentado respostas bem diversificadas, algumas apontando claramente o trabalho como origem do sintoma e outras não. Independentemente da percepção da causa da dor, somente cinco entrevistados (entre os 27 que relataram sentir dor) faltaram ao trabalho devido a esse sintoma. Os demais relataram que não faltam à feira por sentir dor, indo trabalhar até quando adoecem. Mesmo entre os participantes que já faltaram ao trabalho, o período para repouso e/ou tratamento não ultrapassou três dias. Esses dados remetem à relação direta entre dia trabalhado na feira e remuneração, o que é uma realidade nos perfis de feirantes identificados. Além disso, a condição de informalidade dos feirantes, que não têm seguridade social ou qualquer forma de proteção à saúde no trabalho, também deve ser considerada. Um dia sem trabalhar por doença pode significar, além de um dia perdido de remuneração, gastos adicionais com a saúde.

Os resultados de uma pesquisa realizada por Díaz et al. (2008), com vendedores ambulantes no Chile, indicaram que os trabalhadores ficam submetidos a ambientes insalubres de trabalho e adoecem física e psicologicamente várias vezes ao mês. No entanto, se ausentam do trabalho pouco mais de um dia por mês. Em outra situação de trabalho, o de pescadores e catadores de caranguejo da Baía de Guanabara, Rosa e Mattos (2010) relatam que 52\% dos trabalhadores, mesmo doentes ou acidentados, não se afastavam do trabalho devido à sua condição informal.

É interessante notar que nas entrevistas realizadas não foi feita nenhuma associação entre as condições precárias de trabalho, as queixas de dor e a situação de informalidade. Esses dados se alinham ao que foi evidenciado na pesquisa com trabalhadores da construção civil e trabalhadoras domésticas, na informalidade, que percebiam no ambiente de trabalho fatores de riscos à saúde, porém não associavam tal condição ao vínculo informal (Iriart et al., 2008). É possível supor que fatores subjetivos podem estar influenciando esse tipo de percepção. Como destaca Cockell e Perticarrari (2011), trabalhadores informais "parecem 'resignados' com a desproteção imposta pelo trabalho não regularizado; por vezes trazem uma ideia fatalista relacionada com destino, com certo teor de autoculpabilização" (p. 1712).

Este estudo se propôs a investigar o trabalho exercido em um contexto de informalidade, bem longe do modelo de emprego assalariado e formal, tal como assinalado por Spink (2009). Para tanto, teve o objetivo de 
descrever a situação de trabalho de feirantes que atuam na informalidade no espaço de uma feira de confecções na cidade de Fortaleza (CE), assim como levantar indícios de impactos dessa realidade em sua saúde.

O perfil sociodemográfico dos participantes da pesquisa foi bastante variado no que se refere à idade, à escolaridade, à renda e ao tempo de trabalho no ramo. Esse achado corrobora dados da literatura que sugerem que a informalidade é um fenômeno complexo e difícil de ser delimitado, tendo em vista a diversidade de trabalhadores e de ocupações que podem ser encontradas nessa categoria (Costa, 2010). Especialmente a desigualdade na renda relatada pelos trabalhadores é um reflexo da diversidade de inserções e atuações entre os feirantes, que podem atuar de forma instável e descontínua como diaristas ou como donos de bancas com alto rendimento mensal.

Identificou-se que um elemento importante na configuração da situação de trabalho dos feirantes é a categoria do trabalho, que define a organização de responsabilidades, tarefas, instrumentos, horários e hierarquias e criam formas diferenciadas de ser feirante. $O$ tipo de inserção do trabalhador na feira depende de sua posição como fabricante, comerciante ou vendedor. Outro elemento que influencia a situação de trabalho dos feirantes é o local onde se situa o seu ponto de venda. Os espaços do galpão e do shopping são considerados, pelos feirantes, locais mais seguros, embora ainda com a percepção da necessidade de melhorias em sua estrutura. No espaço da rua predominam condições laborais mais precárias, com exposição aos riscos do trabalho a céu aberto e a necessidade de montagem e desmontagem da barraca em cada período da feira. Além disso, são constantemente ameaçados pelas ações de reordenamento do espaço público feitas pela prefeitura, podendo perder seu local de venda e até as mercadorias. Assim, os feirantes com pouca rentabilidade ou inserção recente na feira buscam oportunidades de trabalho no espaço da rua, enquanto aqueles com mais condição econômica buscam o espaço dos galpões.

Como elemento comum, os feirantes submetem-se a extensas jornadas de trabalho, em condições mais ou menos precárias dependendo do local da banca. Como indício das decorrências negativas dessa situação, a maioria dos entrevistados admite sentir dores osteomusculares, independente da categoria e local de trabalho. Entretanto, poucas foram as associações diretas com a atividade desempenhada e poucos os casos de faltas aos dias de realização da feira para descanso ou tratamento médico, o que sugere a supremacia da necessidade de trabalho em relação à saúde e ao bem-estar do feirante no contexto da informalidade. A percepção dos feirantes sobre suas condições de trabalho, sem poder faltar quando estão adoentados, é vista com aceitação e naturalidade, como algo que faz parte da atividade informal, exercendo pouca influência ou mudança no seu dia a dia na feira.

Considera-se que, no caso estudado, a construção de determinadas formas de ordenamento do trabalho no ambiente da feira indica uma capacidade de autonomia e organização efetivada pelos trabalhadores, mas não suprime a condição de precariedade e de informalidade em que estão inseridos. A complexidade das práticas laborais na feira sugere, ainda, a necessidade de novas pesquisas nesse campo para melhor entendimento das relações desenvolvidas entre os feirantes, sua capacidade coletiva e espontânea de implantação de estratégias de organização e suas vivências sobre o trabalho informal e a saúde.

\section{REFERÊNCIAS}

Abrahão, J., Sznelwar, L., Silvino, A., Sarmet, M., \& Pinho, D. (2009). Introdução à ergonomia: Da prática à teoria. São Paulo: Blucher.

Alves, M. A., \& Tavares, M. A. (2006). A dupla face da informalidade do trabalho: "Autonomia" ou precarização. In R. Antunes (Org.), Riqueza e miséria do trabalho no Brasil. São Paulo: Boitempo.

Antunes, R. (2008). O trabalho e seus sentidos. Confluências - Revista Interdisciplinar de Sociologia e Direito, 10(1), 43-61.

Araújo, A. M. C., \& Lombardi, M. R. (2013). Trabalho informal, gênero e raça no Brasil do início do século XXI. Cadernos de Pesquisa, 43(149), 452-477. doi: http://dx.doi.org/10.1590/s0100-15742013000200005

Assunção, A. Á. (2003). Uma contribuição ao debate sobre as relações saúde e trabalho. Ciência \& Saúde Coletiva, 8(4), 10051018. http://dx.doi.org/10.1590/s1413-81232003000400022

Barroso, P. F. (2011). "Conquistei meu espaço dia a dia": Estudo etnográfico sobre a ocupação do espaço público pelos vendedores ambulantes. Revista Habitus, 8(2), 109-119.

Cacciamali, M. C. (2000). Globalização e processo de informalidade. Economia e Sociedade, 14, 153-174. 
Chaves, R. (2012). Cidade ambulante. Universidade Pública da UFC, 12(66), 32-35.

Cockell, F. F., \& Perticarrari, D. (2011). Retratos da informalidade: A fragilidade dos sistemas de proteção social em momentos de infortúnio. Ciência \& Saúde Coletiva, 16(3), 1709-1718. doi: http://dx.doi.org/10.1590/s1413-81232011000300008

Conserva, M. S. (2004). O labirinto da atividade ambulante na cidade de João Pessoa. In A. Araújo, M. F. Alberto, M. Y. Neves \& M. Athayde (Orgs.), Cenários do trabalho: Subjetividade, movimento e enigma. Rio de Janeiro: DP\&A.

Costa, G. V. L. D. (2013). A Feira Bras-Bol em Corumbá (MS): Notas sobre o comércio informal na fronteira Brasil-Bolívia. Revista Semestral do Departamento e do Programa de Pós-Graduação em Sociologia da UFSCar, 3(2), 467-489.

Costa, M. D. S. (2010). Trabalho informal: Um problema estrutural básico no entendimento das desigualdades na sociedade brasileira. Caderno CRH, 23(58), 171-190. doi: http://dx.doi.org/10.1590/s0103-49792010000100011

Creswell, J. W. (2007). Projeto de pesquisa: Métodos qualitativo, quantitativo e misto. Porto Alegre: Artmed.

Díaz, E. M., Guevara, R. C., \& Lizana, J. L. (2008). Trabajo informal: Motivos, bienestar subjetivo, salud, y felicidad en vendedores ambulantes. Psicologia em Estudo, 13(4), 693-701. doi: http://dx.doi.org/10.1590/s1413-73722008000400007

Ferreira, C., Marques, T., \& Guerra, P. (2015). Feiras e mercados no Porto: Velhos e novos formatos de atividade económica e animação urbana. Revista de Geografia e Ordenamento do Território, 1(8), 75-102. doi: http://dx.doi.org/10.17127/ got/2015.8.005

Filgueiras, L. A. M., Druck, G., \& Amaral, M. F. (2004). O conceito de informalidade: Um exercício de aplicação empírica. Caderno CRH, 17(41), 211-229.

Galeazzi, I. (2006). Precarização do trabalho. In A. D. Cattani \& L. Holzmann (Orgs.), Dicionário de trabalho e tecnologia (pp. 259-265). Porto Alegre: Editora da UFRGS.

Garcia, M. R. V., Segre, A., Baccaro, A. F., Silva, L. M., Costa, L., \& Cândido, M. S. (2010). "Mulheres guerreiras": Identidade feminina e profissional entre vendedores ambulantes da cidade de São Paulo. Cadernos de Psicologia Social do Trabalho, 13(1), 27-42. doi: http://dx.doi.org/10.11606/issn.1981-0490.v13i1p27-42

Guimarães, R. R., \& Mesquita, H. A. D. (2009). Feira camponesa: Instrumento de lucha y resistencia de la mujer campesina en Catalão - GO. Anais eletrônicos do XIX Encontro Nacional de Geografia Agrária. São Paulo: Universidade de São Paulo. Recuperado de http://www.geografia.fflch.usp.br/inferior/laboratorios/agraria/Anais\%20XIXENGA/artigos/Guimaraes_RR.pdf

Instituto Brasileiro de Geografia e Estatística. (2013). Primeiros resultados da Pesquisa Nacional por amostra de Domicílios Contínua: PNAD/IBGE, 2012 e 2013. Brasília: IBGE. Recuperado de ftp://ftp.ibge.gov.br/Trabalho_e_Rendimento/Pesquisa_ Nacional_por_Amostra_de_Domicilios_continua/Fasciculos_Indicadores_IBGE/pnadc_201302caderno.pdf

Iriart, J. A. B., Oliveira, R. P. D., Xavier, S. D. S., Costa, A. M. D. S., Araújo, G. R. D., \& Santana, V. S. (2008). Representações do trabalho informal e dos riscos à saúde entre trabalhadoras domésticas e trabalhadores da construção civil. Ciência \& Saúde Coletiva, 13(1), 165-174. doi: http://dx.doi.org/10.1590/s1413-81232008000100021

Krein, J. D., \& Proni, M. W. (2010). Economia informal: Aspectos conceituais e teóricos. Brasília: OIT - Escritório da OIT no Brasil. Recuperado de http://www.oitbrasil.org.br/node/241

Lima, J. C., \& Conserva, M. S. (2006). Redes sociais e mercado de trabalho: Entre o formal e o informal. Revista de Ciências Sociais - Política \& Trabalho, 24, 73-98.

Lira, S. M. D. (2008). Os aglomerados de micro e pequenas indústrias de confecções do agreste/PE: Um espaço construído na luta pela sobrevivência. Revista de Geografia da UFPE, 23(1), 98-114.

Lomba, R. M., \& Nobre-Júnior, B. B. (2013). A relação rural-urbano a partir das cidades ribeirinhas: O papel do comércio popular (feiras) na cidade de Afuá (PA). Confins - Revue Franco-Brésilienne de Géographie, 18. doi: http://dx.doi.org/10.4000/ confins. 8405

Minayo-Gomez, C., \& Thedim-Costa, S. M. F. (1997). A construção do campo da saúde do trabalhador: Percurso e dilemas. Cadernos de Saúde Pública, 13(Suppl. 2), S21-S32. doi: https://dx.doi.org/10.1590/S0102-311X1997000600003

Navarro, V. L., \& Prazeres, T. J. (2010). Reestruturação produtiva, precarização e saúde do trabalhador na indústria de calçados de Franca (SP). In E. Lourenço, V. Navarro, I. Bertani, J. F. S. Silva \& R. Sant'ana (Orgs.), O avesso do trabalho II: Trabalho, precarização e saúde do trabalhador (pp. 179-196). São Paulo: Expressão Popular.

Pochmann, M. (2012). Nova classe média? O trabalho na base da pirâmide social brasileira. São Paulo: Boitempo.

Ramos, J. O. (2008). Vitrines da periferia: Um breve olhar sobre o híbrido e o kitsh expostos na feira da cidade operária. Revista Cambiassu, 18(4), 208-232.

Rezende, C. B. (2001). Os limites da sociabilidade: "Cariocas" e "nordestinos" na Feira de São Cristóvão. Estudos Históricos, 28, 167-181. 
Rocha, S. (2003). A investigação da renda nas pesquisas domiciliares. Economia e Sociedade, 12(21), $205-224$.

Rosa, M. F. M., \& Mattos, U. A. O. (2010). A saúde e os riscos dos pescadores e catadores de caranguejo da Baía de Guanabara. Ciência \& Saúde coletiva, 15(1), 1543-1552. doi: http://dx.doi.org/10.1590/s1413-81232010000700066

Salvitti, A., Viégas, L. S., Mortada, S. P., \& Tavares, D. S. (1999). O trabalho do camelô: Trajetória profissional e cotidiano. Cadernos de Psicologia Social do Trabalho, 2, 1-23. doi: http://dx.doi.org/10.11606/issn.1981-0490.v2i0p1-23

Santos, A. R. D. (2005). A feira livre da Avenida Saul Elkind em Londrina-PR. Geografia: Revista do Departamento de Geociências, 14(1), 145-160.

Santos, M. C., Silva, E. S., \& Silva, J. B. (2011). Dinâmica socioeconômica e a formação de territórios no centro de Fortaleza-CE: O beco da poeira e a feira da Sé. Revista Geográfica de América Central, 2(47E), 1-13.

Sato, L. (2007). Processos cotidianos de organização do trabalho na feira livre. Psicologia \& Sociedade, 19(n.spe), 95-102. doi: http://dx.doi.org/10.1590/s0102-71822007000400013

Silva, F. C. F. D. (2003). Mercado varejista: Um estudo das feiras livres no município de Campinas - SP. Cadernos da FACECA, $12(2), 35-51$.

Souza, J. (2010). Os batalhadores brasileiros nova classe média ou nova classe trabalhadora? Belo-Horizonte: Editora UFMG.

Spink, P. K. (2009). Micro cadeias produtivas e a nanoeconomia: Repensando o trabalho decente. Cadernos de Psicologia Social do Trabalho, 12(2), 227-241. doi: http://dx.doi.org/10.11606/issn.1981-0490.v12i2p227-241 